\title{
Screening for Hepatitis C Virus (HCV) Infection in Acute Lymphoblastic Leukemia (ALL) Survivors in The Hematology and Oncology Department of Children Hospital Zagazig University
}

\author{
Laila Metwaly Sherief ${ }^{1}$, Mohamed AbdelKader Elmalky ${ }^{1}$, Sameh Saber Bayoumi ${ }^{2}$, Sherif Mamdoh Talat ${ }^{* 1}$ \\ Departments of ${ }^{1}$ Pediatrics and ${ }^{2}$ Radiology - Faculty of Medicine, Zagazig University \\ *Corresponding author: Sherif Mamdoh Talat; Email: dr-s@windowslive.com; Mobile: (+20)01111422050
}

\begin{abstract}
Background: Acute lymphoblastic leukemia (ALL) survivors received blood transfusions for multiple times during treatment are at great risk for HCV infection. Rapid progression to cirrhosis in those patients is a concern for cancer survivors because of the immunosuppression from cancer-related treatment.

Objective: Our study aimed to screen for (HCV) infection in acute lymphoblastic leukemia (ALL) survivors.

Patients and methods: This cross-sectional study was conducted in the Hematology and Oncology Department of Children Hospital-Zagazig University on 80 cancer survivors collected over a period of 6 months from September 2018 to February 2019.

Results: $70 \%$ of ALL survivors were HCV positive.

Conclusion: ALL survivors are at great risk for acquiring HCV infection from the repeated blood and blood products transfusions with supsequent development of liver comorbitidites later on.
\end{abstract}

Keywords: HCV, ALL Childhood cancer.

\section{INTRODUCTION}

Hepatitis $\mathrm{C}$ virus (HCV) is a small singlestranded RNA virus. It is considered as the leading cause of chronic infectious hepatitis in children. It is also considered as a major health and economic burden in children in both developed and developing countries. Egypt is one of the countries with the highest prevalence of HCV infection in the world ${ }^{(\mathbf{1})}$.

ALL survivors who received blood transfusions were potentially exposed to hepatitis $\mathrm{C}$ virus (HCV) prior to second-generation screening of blood products in July 1992. Alternatively, this population may have been exposed to HCV through other mechanisms, such as intravenous drug use (2). Symptoms of HCV infection are often indistinguishable from other chronic diseases, but adverse outcomes of chronic HCV infection are common. Rapid progression to cirrhosis is a concern for ALL survivors because of immunosuppression from cancer-related treatment. Nevertheless, limited evidence is available about long-term incidence of cirrhosis in this population ${ }^{(3)}$.

Diagnosis of HCV infection in children with cancer especially with hematological malignancies is more challenging than diagnosis in normal children as the former can have false negative results of serological tests using antibodies against $\mathrm{HCV}$ due to immunosuppression. In some of severly immunocompromised patients, conventional detection of anti-HCV antibodes is not sufficient for diagnosis, necessitating polymerase chain reaction (PCR) analysis for HCV RNA quantification in blood to identify patients with occult infection ${ }^{(4)}$.
Our study aimed to screen for hepatitis C virus (HCV) infection in acute lymphoblastic leukemia (ALL) survivors.

\section{SUBJECTS AND METHODS}

This cross-sectional study was conducted in the Hematology and Oncology Department of Children Hospital-Zagazig University on 80 cancer survivors as cases collected over a period of 6 months from September 2018 to February 2019.

Ethical approval:

This study was approved by the Institutional Review Board (IRB) and was done after ethical approval of the ethical committee of research centre in Zagazig University Hospital and informed written parental consent from every subject that participated in this work.

Inclusion criteria:

1. Children with acute lymphoblastic leukemia (ALL) who had finished their treatment for at least 2 years.

2. Their age was less than 18 years.

3 . Both sexes were involved.

\section{Exclusion criteria:}

1. Newly diagnosed cancer cases.

2. Cancer cases on chemotherapy.

3. Cases of chronic hepatic problems.

All subjects were subjected to the following:

Full clinical assessment:

$>$ Full history taking:

- Age, sex and residency.

- Time of start of chemotherapy.

- Protocol of therapy.

- Duration of follow up.

This article is an open access article distributed under the terms and conditions of the Creative Commons Attribution (CC BY-SA) license (http://creativecommons.org/licenses/by/4.0/) 
- History of HCV infection.

$>$ Complete physical examination including:

Full clinical examination:

A) Vital signs: Heart rate, blood pressure both systolic (SBP) and diastolic blood pressures (DBP) were measured.

B) Anthropometric measurements: Including weight, height and estimation of body mass index (BMI) according to following equation $\mathrm{BMI}=$ weight $(\mathrm{kg}) /$ height $\left(\mathrm{m}^{2}\right)$.

C) Chest, heart, neurological and abdominal examination.

\section{Laboratory investigations:}

HCV Quantification by PCR.

Complete blood count.

Liver and kidney function tests.

Statistical analysis

Recorded data were analyzed using the statistical package for social sciences, version 22.0 (SPSS Inc.,
Chicago, Illinois, USA). Quantitative data were expressed as mean \pm standard deviation (SD). Qualitative data were expressed as frequency and percentage. The following tests were done:

- Independent-samples t-test of significance was used when comparing between two means.

- Chi-square $\left(\mathrm{x}^{2}\right)$ test of significance was used in order to compare proportions between two qualitative parameters.

- The confidence interval was set to $95 \%$ and the margin of error accepted was set to $5 \%$. The pvalue was considered significant as the following:

- Probability (P-value)

- $\quad$ P-value $\leq 0.05$ was considered significant.

- P-value < 0.001 was considered as highly significant.

- P-value > 0.05 was considered insignificant.

\section{RESULTS}

Table (1): Demographic and clinical all survivors

\begin{tabular}{|c|c|c|c|}
\hline \multicolumn{2}{|c|}{ Variable } & \multicolumn{2}{|c|}{ ALL survivors $(n=80)$} \\
\hline Age at follow up (ys) & Mean \pm SD & \multicolumn{2}{|c|}{$11.1 \pm 2.7$} \\
\hline Age at diagnosis (ys) & Mean \pm SD & \multicolumn{2}{|c|}{$6.9 \pm 2.7$} \\
\hline Duration of follow up & Mean \pm SD & \multicolumn{2}{|c|}{$4.2 \pm 1.9$} \\
\hline Weight (kg) & Mean \pm SD & \multicolumn{2}{|c|}{$34.1 \pm 12.9$} \\
\hline Height $(\mathrm{cm})$ & Mean \pm SD & \multicolumn{2}{|c|}{$128.6 \pm 13.4$} \\
\hline BMI $\left(\mathrm{kg} / \mathrm{m}^{2}\right)$ & Mean \pm SD & \multicolumn{2}{|c|}{$19.7 \pm 5.3$} \\
\hline & & No. & $\%$ \\
\hline \multirow[t]{2}{*}{ Sex } & Male & 42 & 52.5 \\
\hline & Female & 38 & 47.5 \\
\hline \multirow{2}{*}{ Type of leukemia } & B cell & 65 & 81.2 \\
\hline & $\mathrm{T}$ cell & 15 & 18.8 \\
\hline \multirow{2}{*}{ Hepatomegally } & Yes & 11 & 13.8 \\
\hline & No & 69 & 86.2 \\
\hline
\end{tabular}

ALL: Acute lymphoblastic leukemia

This table showed that the mean age at diagnosis was $6.9 \pm 2.7$ years while the mean duration of followup was 4.2 $\pm 1.9 . \mathrm{HCV}$ was positive in $70 \%$ of cases.

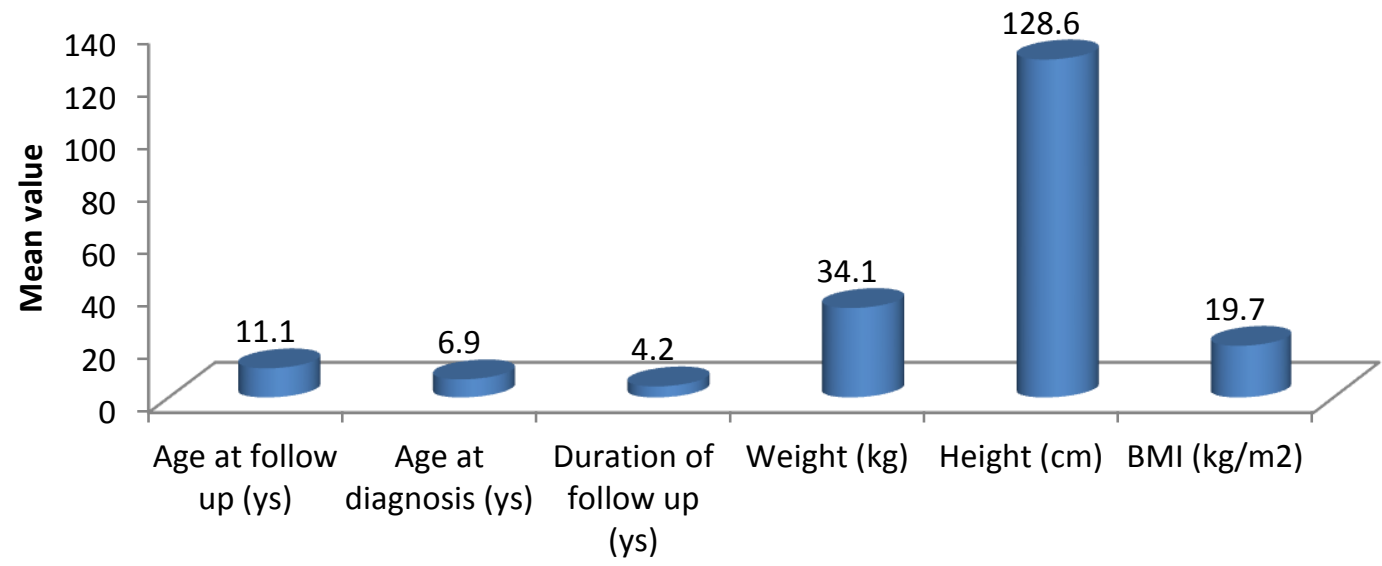

Figure (1): Bar charts showing some personal data of the ALL survivors 
Table (2): Prevalence of HCV infection among ALL survivors

\begin{tabular}{|c|c|c|}
\hline & NO. & \% \\
\hline HCV Positive & 56 & 70 \\
\hline HCV Negative & 24 & 30 \\
\hline
\end{tabular}

This table showed that HCV infection was positive in $70 \%$ of ALL survivors.

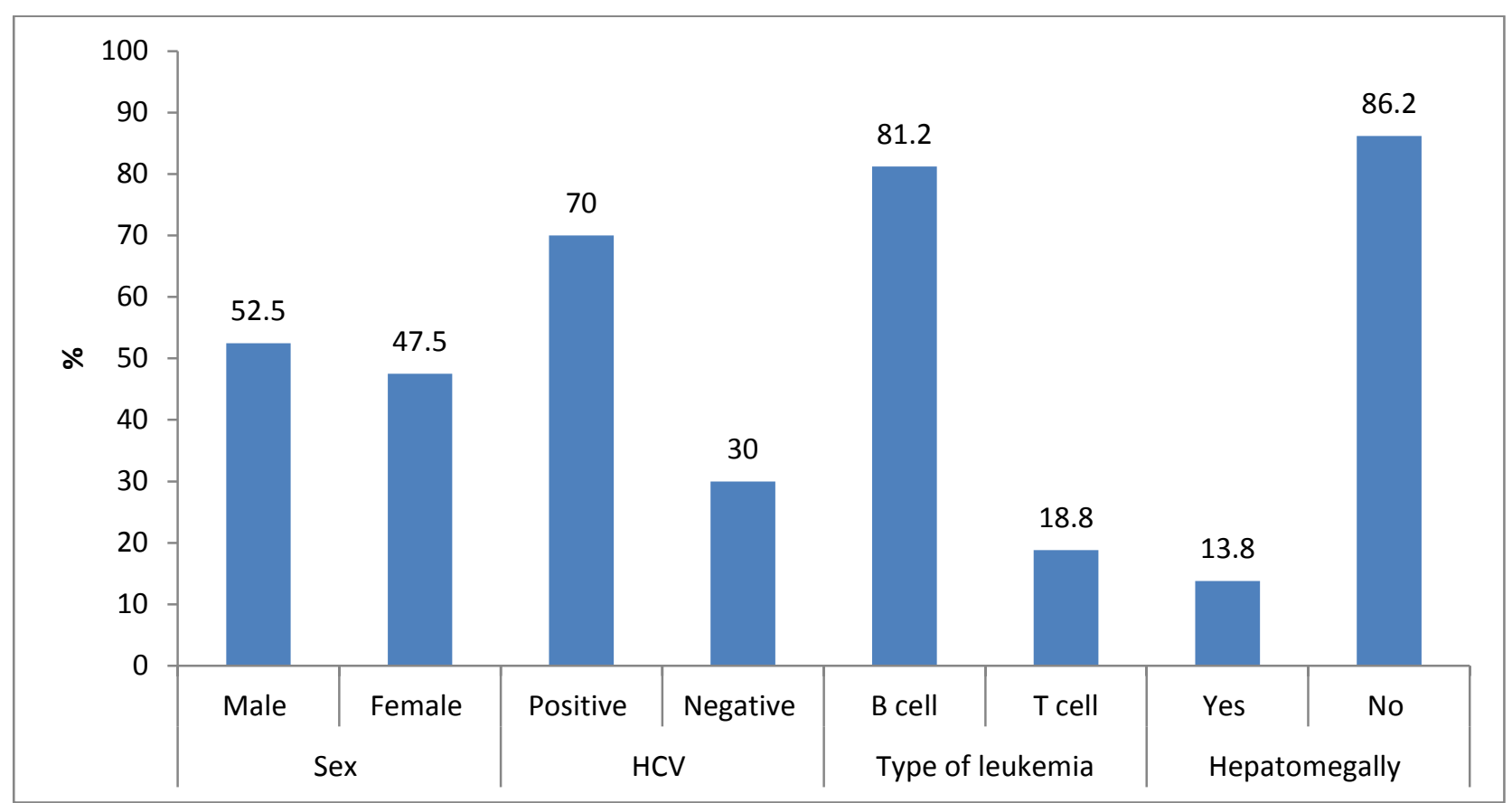

Figure (2): Bar charts showing some personal data of the ALL survivors

Table (3): Comparison of the hematological parameters of the studied groups

\begin{tabular}{|c|c|c|c|c|c|c|}
\hline \multirow{2}{*}{ Variable } & \multicolumn{2}{|c|}{ ALL Survivors $(n=80)$} & \multicolumn{2}{|c|}{ Controls $(n=40)$} & \multirow{2}{*}{$\begin{array}{c}\text { St."t" } \\
\text { test }\end{array}$} & \multirow{2}{*}{$\mathbf{P}$} \\
\hline & Mean \pm SD & Range & Mean \pm SD & Range & & \\
\hline $\mathrm{Hb}(\mathrm{gm} / \mathrm{dl})$ & $11.9 \pm 0.90$ & $0-13.8$ & $12.0 \pm 0.62$ & 11.2-13.1 & 0.47 & $0.64(\mathrm{NS})$ \\
\hline WBCs $\left(\times 10^{3}\right)$ & $7.26 \pm 1.94$ & $3.7-13.1$ & $7.33 \pm 1.69$ & $5.2-10.3$ & 0.19 & $0.85(\mathrm{NS})$ \\
\hline PLTs $\left(\mathbf{x 1 0 ^ { 3 } )}\right.$ & $273.0 \pm 60.53$ & $151-405$ & $283.6 \pm 49.65$ & $215-373$ & 0.95 & $0.34(\mathrm{NS})$ \\
\hline
\end{tabular}

This table showed that there was no statistical significant difference between ALL survivors \& controls as regard WBCs, HB and PLTs.

Table (4): Comparison of the biochemical parameters of the studied groups

\begin{tabular}{|c|c|c|c|}
\hline \multirow{2}{*}{ Variable } & \multicolumn{3}{|c|}{ Controls $(\mathrm{n}=40)$} \\
\cline { 2 - 4 } & Mean $\pm \mathrm{SD}$ & Mean $\pm \mathrm{SD}$ & $\mathrm{p}$ \\
\hline ALT $(\mathrm{U} / \mathrm{L})$ & $40.2 \pm 4.8$ & $21.7 \pm .82$ & $0.003(\mathrm{~S})$ \\
\hline AST $(\mathrm{U} / \mathrm{L})$ & $38.6 \pm 4.4$ & $24.5 \pm 2.7$ & $0.779(\mathrm{NS})$ \\
\hline Albumin $(\mathrm{g} / \mathrm{L})$ & $4.34 \pm 0.32$ & $4.38 \pm 0.26$ & $0.773(\mathrm{NS})$ \\
\hline Total Bil. $(\mu \mathrm{mol} / \mathrm{L})$ & $0.59 \pm 0.15$ & $0.61 \pm 0.19$ & $0.750(\mathrm{NS})$ \\
\hline Direct Bil. $(\mu \mathrm{mol} / \mathrm{L})$ & $0.16 \pm 0.06$ & $0.17 \pm 0.055$ & $0.018(\mathrm{NS})$ \\
\hline Creatinine $(\mathrm{mg} / \mathrm{dL})$ & $0.59 \pm 0.15$ & $0.53 \pm 0.14$ & \\
\hline
\end{tabular}

This table showed that no statistical significant difference between ALL survivors \& controls as regard Bl.urea, creatine, direct bil. and total bil. While there was statistical significant difference between the two groups as regards ALT \& AST.

\section{DISCUSSION}

Our work aimed to assess the prevalence of $\mathrm{HCV}$ infection in ALL survivors and to detect the risk factors for it. This study was performed in the
Outpatient Clinic of Hematology and Oncology Unit, Zagazig University Children Hospital on 80 ALL survivors who had finished chemotherapy for at least 2 years. Eighty one percent of ALL survivors were 
diagnosed as B cell leukemia while $18.8 \%$ were diagnosed as $\mathrm{T}$ cell leukemia this findings were in agreement with Dores et al. ${ }^{(5)}$. The age of our patients at the study ranged from 6-16 years while their age at diagnosis were 1-12 years while the mean duration of follow up of $4.2 \pm 1.9$ years.

Pediatric cancer patients are at higher risk of $\mathrm{HCV}$ infection, as they require multiple blood and blood products transfusions during intensive therapy, frequent blood sampling, intravenous diagnostic procedures, intravenous fluid therpay and surgery.

$\mathrm{HCV}$ infection rate among Egyptian children treated for malignancy ranges from $39 \%$ to $43 \%{ }^{(\boldsymbol{6})}$, compared to 1.8 to $5.8 \%$ among children in the developing countries ${ }^{(1)}$.

Unfortunately, $70 \%$ of our ALL survivors developed HCV infection during the course of therapy. This higher prevalence of infection in our studied group may be related partially to more frequent blood and blood products transfusion as ALL patients receive more intensive chemotherapy.

In the present work, $20 \%$ of ALL survivors had abnormal ALT. Another studies by Rossetti et al. ${ }^{(7)}$ and Bresters et al. ${ }^{(8)}$ defined hepatic late adverse effects as 2 times the upper limit of normal and their prevalence ranged from $7.9 \%$ to $44.8 \%$.

The heterogenicity of the results may be related to the different chemotheraputic regimens used in treatment. Also, hepatitis virus infection may be resulted in higher abnormal ALT levels in some studies ${ }^{(9)}$.

\section{CONCLUSION}

- Acute Lymphoblastic leukemia survivors are at great risk for acquiring HCV infection, which may lead to significant liver damage and chronic hepatic failure later on life.

\section{RECOMMENDATIONS}

- Extra care should be given to ALL survivors with focusing on the liver condition upon every follow up visits.
- Good screening system for blood and blood prducts.

- Routine HCV antibody testing should be done to all ALL survivors.

\section{REFERENCES}

1. El-Shabrawi MH, Kamal NM (2013): Burden of pediatric hepatitis C. World Journal of Gastroenterology, 19 (44): 7880.

2. Shepard CW, Finelli L, Alter MJ (2005): Global epidemiology of hepatitis $\mathrm{C}$ virus infection. The Lancet Infectious Diseases, 5 (9): 558-567.

3. Stallings-Smith S, Krull KR, Brinkman TM et al. (2015): Long-term follow-up for incident cirrhosis among pediatric cancer survivors with hepatitis $C$ virus infection. Journal of Clinical Virology, 71: 18-21.

4. Locasciulli A, Testa M, Valsecchi MG et al. (1997): Morbidity and mortality due to liver disease in children undergoing allogeneic bone marrow transplantation: a 10-year prospective study. Blood, 90: 3799-805.

5. Dores GM, Devesa SS, Curtis RE et al. (2012): Acute leukemia incidence and patient survival among children and adults in the United States, 2001-2007. Blood, 119 (1): 34-43.

6. Mostafa A, Ebeid E, Mansour TAREK et al. (2003): Seroprevalence of hepatitis $\mathrm{B}$ and $\mathrm{C}$ in pediatric malignancies. Journal of the Egyptian National Cancer Institute, 15: 33-42.

7. Rossetti F, Zancan L, Bonato MG et al. (1991): Delta virus and childhood leukemia. Pediatric Hematology and Oncology, 8: 23-32.

8. Bresters D, Van Gils IC, Dekker FW et al. (2008): Abnormal liver enzymes two years after haematopoietic stem cell transplantation in children: prevalence and risk factors. Bone Marrow Transplantation, 41: 27-31.

9. Mulder RL, Kremer LC, Koot BG et al. (2013): Surveillance of hepatic late adverse effects in a large cohort of long-term survivors of childhood cancer: prevalence and risk factors. European Journal of Cancer, 49 (1): 185-193. 